\title{
Great Blood Vessel
}

National Cancer Institute

\section{Source}

National Cancer Institute. Great Blood Vessel. NCI Thesaurus. Code C102955.

Any of the major arteries or veins attached to the cardiac atria or ventricles. This includes the aorta, superior and inferior vena cava and the pulmonary arteries and veins. 